\title{
Projecting Clinical Insight From Quality Simulation Data
}

Providing care to the mechanically ventilated patient can present many challenges. Most clinicians agree that maintaining the airway is important, particularly when depending on higher mean airway pressure to maintain adequate oxygenation. ${ }^{1}$ As a result, some health-care providers may be reluctant to manipulate the endotracheal tube (ETT) in fear of compromising the airway and threatening the patient's gas exchange. It has been suggested that this practice may be associated with the development of pressure ulcer complications. ${ }^{2}$ In the ICU, airway management has evolved to the point where most practitioners now include routine oral decontamination ${ }^{3}$ and avoidance of pressure ulcers (http://www.jointcommission.org, Accessed May 27, 2014) as part of their core practice.

Similarly, health-care providers now routinely position patients (raised head of the bed to reduce ventilator-associated pneumonia) such that the shear forces on the skin around the mouth are increased and that the likelihood of the ETT moving within the trachea is also increased. ${ }^{4}$ With regard to pressure ulcer prevention, one of the recommendations by The Joint Commission is to facilitate mobility. As Fisher et $\mathrm{a}^{5}$ describe in their recent publication, although some devices provide for easier mobility of the ETT (to protect against skin breakdown due to immobility), these same devices may also exert greater forces on the skin in specific areas of the face. They report the most comprehensive study of this problem to date, providing us with excellent insight into the problem and also some potential solutions.

Although the study is based on a simulation model, their data may be of significant clinical value. They placed a series of pressure sensors throughout the lip area and, when appropriate, in the posterior neck of a mannequin and measured shear forces and displacement of the ETT during simulated routine movements that take place in intubated and mechanically ventilated patients. Some of these movements include elevating the head of the bed by $30^{\circ}$ and moving the head horizontally to either side. ${ }^{4} \mathrm{Al}-$ though their data were based on simulation, their conclusions were generated on 1,600 observations and a series of controls to avoid bias between devices and techniques, leading to an extremely high quality data set. ${ }^{5}$

One may extrapolate these data for clinical application, although ultimate clinical validation will also be required. If the results from this study do correlate with clinical patterns for skin breakdown related to ETT-securing devices, these data could indeed lead to a clinical injury risk assessment tool. The value of this prospective tool could be to pave the way for an intervention that might prevent ETT-related pressure ulcers.

Based on their data, compared with the commercial devices, non-commercial ETT-securing devices and techniques provided the greatest stability of the ETT and less force on the surrounding skin, at the expense of poor mobility. By extrapolation from data presented by Fisher et al, ${ }^{5}$ the risks and benefits between devices may be tailored to

See the Original Study on Page 1315

the individual patient population. Whereas surgical patients may require endotracheal intubation for only a few hours to a few days, patients with debilitating lung disease may require prolonged endotracheal intubation. Perhaps surgical patient populations might benefit from receiving commercial devices in which there are greater associated shear forces on the skin but better mobility. However, patients remaining on a mechanical ventilator may be graduated to devices and techniques associated with less shear force but less mobility as they approach candidacy for tracheostomy. Until now, there have been limited data available to guide us in the selection of airway-securing devices for patients, and we have based our choice on provider preference or purchasing department mandate within the individual institution.

In conclusion, the study by Fisher et $\mathrm{al}^{5}$ is the largest study to date of both commercial and non-commercial ETT-securing devices and techniques. Although their data were generated using a simulation model, the study identified significant differences between the available devices. While we await clinical confirmation of these early in vitro data, we might perhaps begin to anticipate patterns of skin breakdown and intervene accordingly. We applaud the work of these investigators and look forward to the future use of this data set for development of an injury score risk assessment tool that itself might guide development of an effective intervention for ETTrelated pressure ulcers. 
Antonio Hernandez MD

Division of Critical Care Medicine and Cardiothoracic Anesthesiology Department of Anesthesiology Vanderbilt University Medical Center Nashville, Tennessee

\section{Andrew D Shaw MD FRCA FFICM}

Division of Cardiothoracic Anesthesiology Department of Anesthesiology Vanderbilt University Medical Center Nashville, Tennessee

\section{REFERENCES}

1. Briel M, Meade M, Mercat A, Brower RG, Talmor D, Walter SD, et al. Higher vs lower positive end-expiratory pressure in patient with acute lung injury and acute respiratory distress syndrome-systematic review and meta-analysis. JAMA 2010;303(9):865-873.

2. Zaratkiewicz S, Teegardin C, Whitney JD. Retrospective review of the reduction of oral pressure ulcers in mechanically ventilated patients: a change in practice. Crit Care Nurs Q 2012;35(3):247-254.

3. van Nieuwenhoven CA, Buskens E, Bergmans DC, van Tiel FH, Ramsay G, Bonten MJ. Oral decontamination is cost-saving in the prevention of ventilator-associated pneumonia in intensive care units. Crit Care Med 2004;32(1):126-130.

4. Dodek P, Keenan S, Cook D, Heyland D, Jacka M, Hand L, et al. Evidence-based clinical practice guideline for the prevention of ventilator-associated pneumonia. Ann Intern Med 2004;141(4):305-313.

5. Fisher DF, Chenelle CT, Marchese A, Kratohvil J, Kacmarek RM. Comparison of commercial and noncommercial endotracheal tubesecuring devices. Respir Care 2014;59(9):1315-1323. 